\title{
2009s-05 \\ The Impact of Distance on Offshore Business Relationships
}

\author{
Benoit A. Aubert, Suzanne Rivard, \\ Mathieu Templier
}

\section{Série Scientifique \\ Scientific Series}

\author{
Montréal \\ Mars 2009
}

(C) 2009 Benoit A. Aubert, Suzanne Rivard, Mathieu Templier. Tous droits réservés. All rights reserved. Reproduction partielle permise avec citation du document source, incluant la notice (C)

Short sections may be quoted without explicit permission, if full credit, including (C) notice, is given to the source.
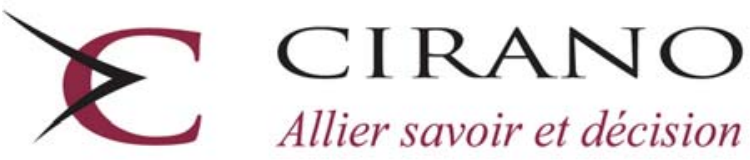

Allier savoir et décision

Centre interuniversitaire de recherche en analyse des organisations 


\section{CIRANO}

Le CIRANO est un organisme sans but lucratif constitué en vertu de la Loi des compagnies du Québec. Le financement de son infrastructure et de ses activités de recherche provient des cotisations de ses organisations-membres, d'une subvention d’infrastructure du Ministère du Développement économique et régional et de la Recherche, de même que des subventions et mandats obtenus par ses équipes de recherche.

CIRANO is a private non-profit organization incorporated under the Québec Companies Act. Its infrastructure and research activities are funded through fees paid by member organizations, an infrastructure grant from the Ministère du Développement économique et régional et de la Recherche, and grants and research mandates obtained by its research teams.

\section{Les partenaires du CIRANO}

\section{Partenaire majeur}

Ministère du Développement économique, de l’Innovation et de l’Exportation

\section{Partenaires corporatifs}

Banque de développement du Canada

Banque du Canada

Banque Laurentienne du Canada

Banque Nationale du Canada

Banque Royale du Canada

Banque Scotia

Bell Canada

BMO Groupe financier

Caisse de dépôt et placement du Québec

DMR

Fédération des caisses Desjardins du Québec

Gaz de France

Gaz Métro

Hydro-Québec

Industrie Canada

Investissements PSP

Ministère des Finances du Québec

Power Corporation du Canada

Raymond Chabot Grant Thornton

Rio Tinto Alcan

State Street Global Advisors

Transat A.T.

Ville de Montréal

\section{Partenaires universitaires}

École Polytechnique de Montréal

HEC Montréal

McGill University

Université Concordia

Université de Montréal

Université de Sherbrooke

Université du Québec

Université du Québec à Montréal

Université Laval

Le CIRANO collabore avec de nombreux centres et chaires de recherche universitaires dont on peut consulter la liste sur son site web.

Les cahiers de la série scientifique (CS) visent à rendre accessibles des résultats de recherche effectuée au CIRANO afin de susciter échanges et commentaires. Ces cahiers sont écrits dans le style des publications scientifiques. Les idées et les opinions émises sont sous l'unique responsabilité des auteurs et ne représentent pas nécessairement les positions du CIRANO ou de ses partenaires.

This paper presents research carried out at CIRANO and aims at encouraging discussion and comment. The observations and viewpoints expressed are the sole responsibility of the authors. They do not necessarily represent positions of CIRANO or its partners. 


\title{
The Impact of Distance on Offshore Business Relationships
}

\author{
Benoit A. Aubert ${ }^{*}$, Suzanne Rivard ${ }^{\dagger}$, Mathieu Templier $^{\ddagger}$
}

\section{Résumé / Abstract}

La délocalisation des activités permet parfois de réduire le coût de ces activités. En même temps, cette délocalisation génère des coûts de gestion additionnels. Cet article développe un modèle expliquant les principaux facteurs qui influencent l'effort de gestion requis pour gérer des activités à distance. Les résultats montrent que la distance a un rôle important. Toutefois, ce n'est pas simplement la distance géographique ou culturelle mais plutôt une « distance perçue » qui semble le facteur déterminant. Les technologies de l'information facilitent la formalisation de l'information échangée et réduisent l'impact de la distance sur l'effort de gestion.

Mots clés : délocalisation, distance, technologies de l’information.

Offshoring can reduce the production cost of an activity. At the same time, it can generate additional management costs. This paper develops a model explaining the main drivers of the efforts required to manage offshore activities. Results show that distance plays an important role in the determination of the effort level. However, it is not simply a cultural or geographical but a more complex notion labelled "perceived distance". IT played an interesting role in the determination of effort. It facilitated a higher formalization of the information exchanged and mitigated the impact of geographical distance on the effort required.

Keywords: Offshoring, distance, information technology.

\footnotetext{
${ }^{*}$ Corresponding author, HEC Montréal and CIRANO, benoit.aubert@hec.ca.

${ }^{\dagger}$ HEC Montréal and CIRANO, suzanne.rivard@hec.ca.

${ }^{\ddagger}$ HEC Montréal and CIRANO, mathieu.templier@hec.ca.
} 


\section{Introduction}

The phenomenon of globalization and the recent opening of new markets have transformed the environment within which organizations operate. Organizations are frequently forced by strong competitive pressures to overcome new hurdles arising from a deteriorating balance of power with their clients (Baily and Farrell, 2004; Trefler, 2005). Consequently, it becomes necessary to cut costs and restructure in a perennial quest for new modes of organization that will allow productivity targets to be met.

In a context such as this, some firms will opt to relocate some of their operations. Only recently extending to the service sector, the rationale for offshoring mirrors that for outsourcing-a desire to boost profitability and cut costs more aggressively. The rapid development of IT is seen to create opportunities here, appearing to erase barriers created by distance and opening new horizons to firms.

Intuitively one can anticipate that offshoring an activity might lower production costs while at the same time generate extra costs or efforts in order to manage the activity. However, the key drivers behind these required efforts are not completely understood. This paper seeks to develop a model explaining what are the main antecedents of the efforts required to manage offshore activities. The role of distance and the effect of technology are investigated.

Data was collected from twelve organizations offering services to clients in a wide variety of countries. The respondents were based in three main regions: Atlantic Canada, Western Europe, and Eastern Europe.

Results show that distance plays an important role in the determination of the effort level. However, it is not simply a cultural or geographical distance that influences the effort. A notion of perceived distance emerged from the interviews. This construct depended on the traditional components of distance as well as the quality of the relationship history between the client and the supplier. IT played an interesting role in the determination of effort. It facilitated a higher formalization of the information exchanged and mitigated the impact of geographical distance on the effort required.

\subsection{Context}

Trade in services has nearly doubled during the past ten years (Jensen and Kletzer, 2005). This pattern echoes the trend we observed during the heyday of offshoring manufacturing activities (Van Welsum and Reif, 2005). Van Welsum and Reif (2005) demonstrate that certain sectors, including business services, financial services, and a variety of administrative support services are more vulnerable than others to this phenomenon.

Trefler (2005) recognizes that offshoring hinges on two central factors: improvements in the IT sector and advancing policies of openness in developing countries. 
Extraterritorial offshoring raises concerns regarding employment. According to Forrester Research Inc., 3.3 million administrative jobs will be affected by extraterritorial offshoring by the year 2015 (Drezner, 2004). The long-term fallout of offshoring could be positive-the overall share of U.S. jobs affected will only be about $0.2 \%$ annually. The ensuing savings may, in turn, fund new investments in the economy.

Benefits to the economies of developing countries can be substantial. Outsourcing certain activities may help some companies remain profitable and spur investments, thus preserving jobs (Baily and Farrell, 2004).

"There is no universal definition of Offshoring" (Trefler, 2005). Some confusion surrounds the concept of offshoring. Outsourcing is a management mode that externalizes a firm's activities, partially or in their entirety, to another firm. The phenomenon of offshoring specifically refers to the geographical displacement of the functions or activities. Offshored functions or activities may continue to be managed by the same company. Thus, the two concepts are orthogonal.

Offshoring is not new, but it is currently expanding at an unprecedented rate (Ferguson, Kussmaul, McCracken, and Robert, 2004). According to Drezner (2004), significant recent developments in IT have facilitated, or even made possible, offshoring. Offshored activities are increasingly complex, and offshored services increasingly sophisticated (Trefler, 2005). Workers in low income countries, such as India and China, are now highly qualified (Trefler, 2005) and possess distinctive competencies. IBM, for instance, seeks not only low wages, but also specific skills and a workforce made up of reputable employees (Hamm, 2006).

Offshoring is associated with many objectives, and those frequently mentioned include lower costs, a more flexible workforce that can easily be adjusted according to need, new and distinctive competencies, and the benefits of around-the-clock operations thanks to staggered time zones (Ferguson et al., 2004).

Baily and Farrell (2004) identify costs as the single most important factor in the decision to offshore. This study will seek to explore the role of information technologies (IT) in the structure of management costs of offshored activities.

\section{Conceptual background}

In some ways, recent offshoring events are simply a continuation of the reforms and structural shake-ups that organizations have suffered through in the past. According to Coase (1937), transactions costs provide the basic raison d'être of the firm. Besides, costs also exist within firms, such as organization or motivation costs, and monitoring or or surveillance costs (Sappington, 1991). This approach can be used to understand offshoring. While an activity's production cost may be lower when it is offshored, management costs will be higher. We can reasonably assume that it is more difficult to manage an activity from afar than locally. Several factors can make an activity easier or harder to manage from a distance. 
In order to investigate the drivers of the level of effort needed to manage an offshore relationship, two types of drivers are considered: the distance between the parties and the technology used. The information needed to manage the transaction is at the core of the exchange. It is reasonable to think that information will be more difficult to share, track, or measure distantly than locally.

This section discusses the impact each of the above-mentioned factors might have on the effort needed to manage an offshore relationship. Information exchanges will be part of the effort. Parties will need to share details about work, requirements, etc. Because of this information exchange, IT is expected to have a role. As mentioned by Hunt and Morgan (1994), the development and global diffusion of IT has allowed organizations around the world to be interconnected. IT thus plays a facilitating role in the remote management of business relationships. It is expected to lower the effort required to manage activities offshore. At the opposite, the distance, in various forms, is expected to increase the effort required to manage the offshore activities.

The purpose of this theoretical section is to guide subsequent phases of data collection and analysis. It serves as a frame of reference and a benchmark for researchers, so as to guard against using irrelevant data or becoming sidetracked during the analysis. Variables are presented, as well as the apparent relationships between the variables.

\subsection{The effort to manage the relationship}

We expect the effort required to manage the relationship to be analogous to transaction costs. Williamson (1985) suggests that these are costs associated with identifying potential partners, negotiating and enforcing contracts, and following-up on activities. In an offshoring context, we would anticipate additional coordination costs that are specific to this setting. Collecting information on several offshoring companies and multiple business relationships will allow these elements to be identified.

\subsection{Factors influencing the management effort}

According to the literature, the effort required to manage the relationship may be a function of several variables, including the need for information sharing and various distance-related criteria. It depends on the organization's ability to contact and communicate with other organizations. This capability involves the organization's internal resources and, in the case of extraterritorial offshoring, a vital reliance on technology. Consequently, distance should increase the level of difficulty while IT should have a facilitating effect.

\section{a) Distance factors}

In order to understand how distance influences the effort required to manage an offshore activity, it is important to clarify the concept of offshoring distance. Dimensions of distance having been mentioned in the literature include geographic, cultural, and institutional. 
Geography. The geographic dimension of distance designates the space and time separating the physical locations of organizations, suppliers, partners, and clients.

An increase in distance measured in kilometres reduces the potential for direct and face-to-face communication. Geographical distance imposes a supplementary cost on a firm wishing to organize such meetings. Furthermore, Powell, Piccoli, and Ives (2004), when writing about virtual teams, maintain that it is difficult to instil a sense of trust between members of a team if they have never met in person.

Time zone differences compound the issue of distance in kilometres, and for this reason firms sometimes choose to offshore their activities into the same, or a nearby, time zone (Rao, 2004).

However, time zone differences may also be an asset and constitute an incentive to offshore. In some cases, in fact, time zones may allow firms to switch to around-the-clock operations in order to fast-track projects or offer 24-hour service to their customers (Rao, 2004; Powell et al., 2004; Ferguson et al., 2004).

The geographic dimension of distance is seen to increase the cost of trade. Distance, in terms of both kilometres and time zones, is often treated as a risk factor in the literature.

Culture. Cultural distance is defined as a mismatch in terms of the language or values specific to a country or a particular region of the world. Hofstede (1980) defines culture as a "collective programming of the mind" that is shared by all members of a group. According to Hofstede (1980), culture spans a number of dimensions, such as individualism, power distance, uncertainty avoidance, and masculinity. Individualism expresses the level of freedom and independence individuals feel vis-à-vis the group. Power distance captures the level of inequality and the unequal distribution of power within the hierarchical structure. Uncertainty avoidance describes individuals' degree of tolerance to undesirable events that may occur in the future. The degree of masculinity designates people's sensitivity to material vs. emotional factors.

These various dimensions of culture allow us to capture the cultural distance separating two groups. For example, attitudes regarding deference to authority and hierarchy is an important factor in the context of work teams. In India, notably, the issue of authority will be perceived differently by local employees than by Westerners, since it goes to the very heart of how Indian society is structured (Barrett, Drummond, and Sahay, 1996). Thus, cultural distance represents an important risk factor in extraterritorial offshoring. Work in groups embracing several different cultures often encounters difficulties, either at the level of communication and political and hierarchical relationships between groups, or at the level of the comprehension, significance, or envisioning of a goal, a technology, etc. (Barrett, Drummond, and Sahay, 1996; Huntley, 2006).

Communications problems also involve language. One gripe often expressed by U.S. customers with respect to call centres based in India is the accent, which can be hard to understand 
(Punch, 2004). Furthermore, even when the language is the same, definitions or shades of meaning of some words may not be the same everywhere, and words can have multiple senses that vary across cultures.

Cultural distance increases the cost of managing the relationship. A large cultural gap is often perceived as risky to projects (Rottman and Lacity, 2004). In addition, Morgan and Hunt (1994) suggest that developing shared values allows the confidence required for the business relationship to be built.

Institutions. Legal and judicial systems vary across countries and even, to a lesser extent, between administrative divisions within countries-regions, provinces, territories, states. This difference between institutional systems constitutes a risk factor in the context of project offshoring.

Conflict and litigation may arise in these projects. To accommodate this eventuality, the jurisdiction in which lawsuits will be heard should be specified in the contract, but it appears that this is not always done (Huntley, 2006). Most clients would prefer to be governed by the legal system of their own country. In fact, large companies often have their own team of lawyers with a much more thorough understanding of the law in their home jurisdiction. Consequently, adapting to the laws of another country necessitates learning another system and represents a cost, in terms of both the investment of time and the compensation to individuals charged with legal matters. Furthermore, two aspects of the institutional dimension of distance also depend on the geographic dimension: work schedules (Rao, 2004) and national rules of entry (Scott et al., 2004; Rottman and Lacity, 2004).

Legal and judicial compatibility between the two countries must be a factor in the decision to offshore. Considering that the legal framework is perceived as a risk by investors (Rottman and Lacity, 2004), this dimension of distance is liable to have an impact on the offshoring initiative. Institutional distance appears to increase the costs of trade.

In the literature, the various dimensions of distance all seem to be positively correlated with the cost of managing the relationship. Geographical distance imposes supplementary travel costs as well as management and coordination costs with respect to time zones. The literature speaks of the potential for misunderstandings arising out of differences in language and culture. Consequently, consideration must be given to the cost of managing misunderstandings and the inefficiencies they entail. Differences between countries in the area of standards and laws can sometimes create problems and challenges that inflate the cost of the trade.

b) Technology as a facilitator of offshoring

The purpose of the client-supplier relationship is to carry out activities, occasioning the transmission and exchange of information. As a rule, all activities require sharing information (Aubert, Rivard, and Patry, 2004; Rice and Shook, 1990). The type of information needed depends on the activity. 
We can distinguish between two information-related requirements: reduced ambiguity and reduced uncertainty (Daft, Lengel, and Trevino, 1987; Rice and Shook, 1990). Uncertainty is the gap between the amount of information possessed by the organization and the amount required for the activity. Ambiguity measures the clarity of the information and the potential scope for interpretation (Daft et al., 1987). The flow of information between the parties ought to contribute to meeting these needs, since it allows information to be distributed and clarified by explanations and specifications.

Not all activities appear to be candidates for outsourcing or offshoring. If an activity is to be offshored, the costs of production and of managing the remote relationship must be below local production costs, including organization and motivation costs for this activity. Van de Ven and Ferry (1980) envisage two dimensions of the nature of the activity, the level of difficulty and the variability of the task. If the task is both variable and difficult, the literature suggests management effort will increase owing to greater requirements for information. Thus, for example, firms prefer in-house management in the case of transactions characterized by great uncertainty and measurement issues (Aubert, Rivard, and Patry, 2004), as this allows them to ensure conformity of the output and to monitor its production.

As early as 1937, Coase discussed IT as a factor that could allow the size of organizations to increase while cutting internal production costs, including the costs of organization and motivation. In the case of offshoring, a technology suited to the needs of the organization is one that is reliable and high-quality, able to support the operations required to meet its goals (Rao, 2004).

By reducing coordination costs, these technologies have contributed significantly to the proliferation of offshoring (Drezner, 2004). With the opening of new markets and the emergence of new IT, organizations must remain open to change, able to support innovation, and sufficiently flexible in structure to respond to shifts in demand and to competitive threats (Trefler, 2005).

Austin (2005) distinguishes between various technologies on the basis of their return on investment and their width of deployment in the firm. Technologies applicable across all departments, not specific to certain types of task but useful to all, should be deployed as widely as possible. This includes communications and collaboration tools such as e-mail, the telephone, and the Internet. These tools are convenient for conducting research and for transmitting information and data, but are ill-suited for in-depth learning or analysis (Austin, 2005). Other technologies are implemented in a more limited fashion, and only a few users can benefit from them. These tools are essentially transactional applications, in that they process or organize information in a specific manner (Austin, 2005).

Rice and Shook (1990) also distinguish between various communications media on the basis of social presence and the wealth of information they can transmit. Social presence is the perception of the attributes of a medium. This perception depends both on the objective 
characteristics of the medium and on the specific context of the communication (Rice and Shook, 1990). Carlson and Zmud (1999) also evoke the influence of the perceived richness of the media on the efficiency of communication and the reduced frequency of misunderstanding.

IT appears to significantly curb the effect of the aforementioned factors. The organization's ability to communicate with other entities is enhanced by IT (Rao, 2004), confirming their tendency to lessen the effort required to manage the relationship. Communication tools, such as telephone, webmail, instant messaging, online forum and videoconference, are few examples of tools which help to coordinate stakeholders (Powell et al., 2004). IT also makes it easy to communicate with partners over great geographical distances. Indeed, a mix of synchronous (telephone, instant messaging) and asynchronous (e-mail) channels help to face geographical challenges (Pauleen and Yoong, 2001).

Technology does not appear to provide a direct solution to problems associated with cultural distance (Pauleen and Yoong, 2001). The purpose of communications technologies is, however, to facilitate information exchanges, thus potentially engaging on a path of convergence to mutual understanding.

In the specific context of offshoring, IT appears to help stakeholders communicate, despite the distances, thus facilitating the transmission of the information required for the offshore activity. Thus, the impact of IT in any given offshore context will depend on the offshoring distance and the information needs.

\section{Methodology}

A qualitative approach was chose to investigate the phenomenon. The goal of the study was the elaboration of a research model explaining the links between information, the notion of distance, the use of information technology, and the efforts required to manage offshore business relationships. A field study was chosen. This approach had been used in the past in the context of offshoring (Rao et al, 2006). Since the objective was to do theory building, the study was organized along the steps suggested by Eisenhardt (1989).

\subsection{Short stories - Getting started}

As the research question investigates the "how" and "why" of the use of IT in the context of an offshore agreement, a qualitative approach was chosen. Multiple sites were used to gather information about the phenomenon. Face to face interviews were done with respondents involved in the management of offshore activities. Multiple short stories will allow for appropriate variation in the data gathered, and the emergence of general patterns.

\subsection{Selecting respondents}

Twelve organizations were selected for the study. Requirements include geographical and cultural distance between selected organizations and their clients. Four of the firms are located in New-Brunswick (Atlantic Canada), two are located in Belgium, and six are located in Lithuania. Responding firms are performing varied activities, which are: software development, business 
intelligence, call center operations, research and development, and consulting. Table 1 presents geographic location of the firms and their main activities. Figure 1 shows responding firm's relationships with their clients and time zone distribution.

The appropriate selection of the respondents is key to define the limits for generalizing the findings. Thus, choices were made to carry out the study on three distinct geographic locations and in varied activity sectors.

Sampling contains vendors and service suppliers located abroad. Supplier side was preferred for several reasons, in addition to the data accessibility issue. Suppliers do not take the decision to move offshore. However, they have to adapt to their clients and face the relational challenges due to the offshore relationship. Furthermore, there still exists little literature on the supplier side, which suggests an original contribution.

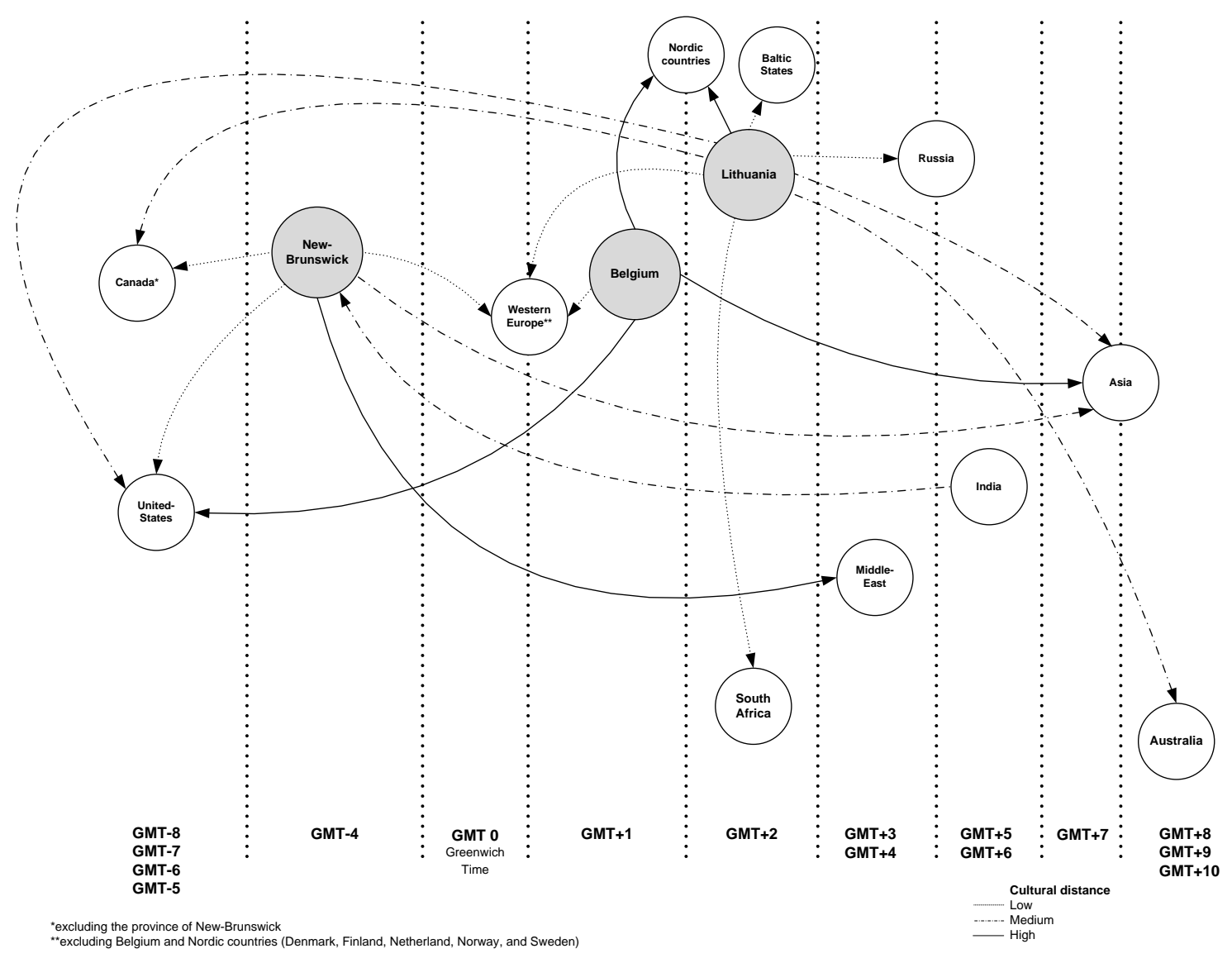

Figure 1 - Responding firm's relationships with their clients and time zone location ${ }^{1}$

${ }^{1}$ Figure 1 distinguishes between 3 levels of distance. These levels were estimated using previously measured Hofstede's scores of the concerned countries (Hofstede, 1984; Ronen and Shenkar, 1985; Naumov and Puffer, 2000; Mockaitis, 2005). Ronen and Shenkar (1985) produced a cluster classification of countries by cultural and attitudinal likeness. For each client-supplier relationship, the differences 
Cultural differences between clients and suppliers were expected considering the geographic distribution of the firms (suppliers and their clients). Cultural distance between respondents' countries was measured with Hofstede's (1984) cultural dimensions, i.e. individualism, power distance, uncertainty avoidance and masculinity. Hofstede's measures have shown to be robust and capture interesting elements in the context of offshoring. For example, Scholtens and Dam (2007) found a positive association between individuality and ethical conduct. However, they could not detect a relation between economic development and ethical policies. This suggests that Hofstede's dimensions might have a significant influence in an offshoring relationship. Initial measurement of cultural distance ensure that the sample contained business relationships with potential cultural differences. This enabled the researchers to investigate on manifestations of the effects of cultural distance on business relationships.

Table 1 - Responding firms by activity

\begin{tabular}{llll} 
& New-Brunswick & Belgium & Lithuania \\
\hline $\begin{array}{l}\text { Software development } \\
\text { Business intelligence }\end{array}$ & AC2 & & EE1; EE5 ; EE6 \\
$\begin{array}{l}\text { Call centers } \\
\text { Research and development }\end{array}$ & AC3; AC4 & & \\
$\begin{array}{l}\text { Consulting } \\
\text { NE2 }\end{array}$ & WE1 & EE2 ; EE3 ; EE4
\end{tabular}

\subsection{Crafting instruments and protocols}

Interviewees belong to three distinct organizational groups; operational, technological and functional levels. Operational level refers to general management, i.e. operations, project management, marketing, or sales. Technological level is in charge of technical development and support. Respondents from the functional level are part of the production line and perform the service activities. Selecting respondents in those three groups allow a better representativeness in collected data.

Data originated from multiple sources: semi-structured interviews, documentation, and observation. Nineteen employees were interviewed across the twelve organizations. Before each interview, available online documentation on responding organizations websites was consulted. The objective was to understand the organizational context of the firm. During interviews, about a third of the respondents gave researchers additional documentation (reports, presentation slides and records, etc.). Additional observations occurred when

between scores (in absolute values) were summed over all dimensions to obtain a measure of the corresponding cultural distance. The resulting interval varies from 0 to 130 . Scores were classified as "Low" from 0 to 65, "Medium" between 65 and 90, and "High" above 90. 
interviewees showed demonstrations of the use of their IT tools. The diversity of sources provided a certain level of triangulation (Benbasat, Goldstein, and Mead, 1987).

After examining the literature, an interview protocol was built. It is provided in Appendix I. Open questions were formulated at the beginning, allowing the researcher to adapt the interview process according to the respondent answers and information already gathered.

\subsection{Entering the field}

The main objective of interviews is to identify and understand the challenges face during performing of an offshore service activity. Interviews allow also to explain the role and use of IT in the context of offshoring. All interviews, lasting approximately ninety minutes, were conducted face-to-face. This method facilitates a certain level of trust between the respondent and the researchers.

All interviews were recorded and transcribed. Data was coded methodically. New questions were added to the interview protocol during the study, to provide additional details on some topics.

Methodology used is iterative and proceed to a constant comparison between data and analysis results, which then allows emergence of new themes to build or improve theory (Eisenhardt, 1989).

\subsection{Analyzing data}

The main objective of iteratively coding data is to develop new concepts, properties and relationships. Analysis then allows shaping a set of categories and associated concepts, describing the phenomena under study.

Based on the research framework, a list of general coding categories was defined. General categories protect the researcher from selecting irrelevant data. Codes were later defined from data and associated to a general category through multiple iterations. Free coding provides flexibility for coding new data and findings. "Incidents accumulated under a label are used later to develop a statement of the concept's nominal definition, theoretical meaning, or substantive content" (Martin and Turner, 1986). A coding template was defined after multiple iterations, agreeing on the list of codes and categories, meanings and coding procedures. Iterations afford validation of new codes and verification of the constant conformity of coding procedure.

Emergence of themes and concepts require multiple iterations. An analysis of each geographic site was performed as data was collected. A first within-site analysis, after completion of the data collection phase in New-Brunswick, shapes new concepts and categories. Inter-site analysis was conducted later, using comparison between each variable and aiming at defining variables, antecedents and consequences. A research model was built and refined along the research process. 


\section{Results}

As expected, information, distance, and information technology had an influence on the level of effort exerted by the respondents to manage an offshore activity. Additional elements were also mentioned. Among them, the most important is the notion of perceived distance. The interviews suggest that distance can be defined is a more holistic way than what was anticipated. These elements are presented in section four.

\subsection{Challenges associated with information needs}

Information needs vary with the activity being offshored. In general terms, any project will require communication and the transfer of information between the stakeholders. The literature distinguishes between two needs that are met by information: reduced ambiguity and reduced uncertainty. Both of these are associated with greater effort invested in communication. To illustrate, one manager spoke of challenges related to performing an activity that is complex and has substantial information needs: "There is a need for communication; there is a need to be very sure of understanding each other, etc. [...] But if the product is extremely complex, exchanges will be longer." (Project Manager, WE1). Numerous respondents also emphasized the need for clarity when communicating with clients or business partners: "We know what we do, and it's very clearly outlined for us, and we know what our goals are. So it's really one step after step, and it has to run like this, with guides here from national office." (Manager, Customer Services and Operations, AC3)

\subsection{Dimensions of distance}

Dimensions of distance having been featured in the literature include geographic, cultural, and institutional. According to the respondents, institutional distance increases the effort of managing the relationship, but the challenges thus created are easily managed. Also, not one of the respondents perceived a linkage between them and technologies. In the interest of brevity, the institutional dimension of distance will not be pursued in this article.

\section{a) Geographical distance}

According to the respondents, geographical distance rarely creates a major obstacle to the accomplishment of their activities, but it does have an impact on the effort of managing the relationship. Distance in terms of both kilometres and time zones imposes efforts of organization and adaptation. "Time differences have an impact on how we organize ourselves" (IT and Global Systems Administrator, WE2). Several respondents mentioned that time differences make communications intermittent and less frequent. Also, one manager spoke of delays in performing activities: "Most of the delays we face are based on time zone. If someone send me an email in the evening, that's at the end of my day work. Then I won't see it until the next day." (Manager, Customer Services and Operations, AC3). Distance in terms of kilometres reduces the potential for face-to-face meetings and can represent a financial cost. 
b) Cultural distance

Two dimensions of cultural distance were addressed during the interviews: country-specific differences in values and differences in language. These two dimensions of cultural distance call for greater effort to manage the relationship. Different values affect behaviour and work habits, requiring efforts of adaptation and understanding. As mentioned by one of the managers: "If you do marketing and sales in Latvia, it will not be the same as if you do business in Russia, [...] because marketing tools are different. [...] We try to devote one person to each market. It's mostly due to the culture, because people understand the same thing differently" (Marketing Executive, EE4). Another manager describes his relationship with contractors: "In India, our subcontractors do everything in their power to comply with the information provided, as they understand it, because sometimes misunderstandings have resulted in mistakes." (Project Manager, AC2). Misunderstandings also arise thanks to differences on the level of language: "To Americans, someone speaking their language seems perfectly natural, so I don't think they always fully appreciate the difficulty some people have speaking a language that is foreign to them and, by extension, picking up some of the required or desired nuances." (IT and Global Systems Administrator, WE2).

\subsection{Technology as a Facilitator of Offshoring}

All respondents agree that technology appears to have an indirect impact on the effort to manage the relationship. Thus, IT helps to confront challenges posed by geographical distance and information needs. According to most respondents, IT has the capacity to accelerate communications tasks and activities and information processing.

a) The impact of IT on the offshoring distance

A majority of respondents recognize the usefulness of technology for overcoming barriers attributable to geographic distance, but do not see any possible impact on other dimensions of distance. One manager clearly enunciated this proposition: "Yes, the technology definitely helps to shrink the distance, geographically. But it doesn't help to shrink the cultural distance." (Customer Account Manager, EE1). Technology renders the message virtual and facilitates the dissemination of information. Thus, it has the effect of smoothing the relationship between geographical distance and the effort to manage the relationship. "Technology makes the geography not an issue. We can deliver to anybody anywhere." (Vice-President Customer Relations, AC1). Synchronous dissemination of information can replace some face-to-face meetings, while asynchronous dissemination allows some barriers created by time zones to be circumvented. Also, one manager comments on his use of e-mail: "Time zones mean that e-mail, or any tool allowing the message to be stored, are much easier to use" (Project Manager, WE1).

b) Effects of IT on information needs

Technology allows information needs to be met more easily by simplifying transmission of, and access to, the required information. "The biggest benefit of the use of technology between us and the client is the dissemination of the information and the archiving of the information. [...] It's completely dependent on the technology for us. And that's a huge factor for us, for them to 
be able to go back and get that information and access it in an organized fashion." (VicePresident Customer Relations, AC1). Furthermore, some technologies allow a clearer presentation of the information and organization of the message contents. For example, one manager mentioned the advantages of e-mail: "Email, I find incredible for clarity. There is nothing missed. You send the email, and you can attach documents." (Vice-President Customer Relations, AC1). Another manager describes his use of office applications: "The planning tools we use allow us to become organized more rapidly, to create more formal presentations, to be prepared fast [...] before the customer arrives. Powerpoint. All these things can make a difference." (Project Manager, AC2).

\subsection{Additional elements mentioned by the respondents.}

a) Perceived distance

The first new element that was revealed through the interview is the notion of perceived distance. In the study, distance was decomposed into three components: cultural distance, geographical distance, and institutional distance. Institutional distance was not really considered by the respondents. It did not seem to cause problems. Cultural and geographical distances were mentioned. However, they were associated with an amalgamated construct. We labelled this construct perceived distance.

Perceived distance is the distance individuals felt existed between himself or herself and a colleague or a partner organization. As presented by the respondents, perceived distance is a mental representation and combine at the same time some cognitive aspects and some relational (or emotional) ones. Perceived distance varied with time.

Interestingly, some of the relational aspects seemed to mitigate the cognitive ones. The perceived distance depended on the perception that there were barriers for social interactions between the individuals. It depended, as expected, on the geographical distance between the individuals collaborating. The geographical component was both attributable to the absolute distance (in kilometres) and on the difference between the time zones. This made the interactions less frequent and more difficult, thus the increased perceived distance. As one manager mentioned: "acquiring a new client who is far, from far away, is almost impossible" (Project Manager, WE1).

b) Message formalization

Another additional element that appeared during the interview is the need for message formalization. The complexity of the activity modifies the level of effort required to process the information associated with the activity. Complexity derives from the activity size (number of steps) and level of structure. This complexity makes formalization of the interaction process more desirable. The increased level of information required to process complex activities motivates managers to structure and organize this information. This minimizes losses of critical information. Moreover, the increased formalization of the message reduces the risks of misunderstanding between the client and the supplier. 
Table 2 summarizes the results:

Table 2 - Results

\begin{tabular}{|c|c|c|}
\hline Relationships & Organizatio & Results \\
\hline \multicolumn{3}{|c|}{ Results consistent with the initial expectations } \\
\hline $\begin{array}{l}\text { Challenges } \\
\text { associated } \\
\text { with } \\
\text { information } \\
\text { needs }\end{array}$ & $\begin{array}{lr}\text { AC2, } & \text { WE1, } \\
\text { WE2, } & \text { EE1, } \\
\text { EE3, } & \text { EE4, } \\
\text { EE6 } & \end{array}$ & $\begin{array}{l}\text { All activities require transferring information between stakeholders. } \\
\text { The quantity of information needed and its degree of ambiguity make } \\
\text { supplementary efforts of communication and clarification necessary. }\end{array}$ \\
\hline $\begin{array}{l}\text { Challenges } \\
\text { associated } \\
\text { with } \\
\text { geographica } \\
\text { I distance }\end{array}$ & $\begin{array}{l}\text { AC1, AC2, } \\
\text { AC3, AC4, } \\
\text { WE1, WE2, } \\
\text { EE1, EE2, } \\
\text { EE3, EE4, } \\
\text { EE5, EE6 }\end{array}$ & $\begin{array}{l}\text { Time zones increase communication lags and diminish flexibility. } \\
\text { Greater distance in } \mathrm{km} \text { increases the number of trips (cost in terms of time and } \\
\text { money). } \\
\text { Time zones and distance in } \mathrm{km} \text { increase the need for planning and organizing. } \\
\text { Time zones and distance in km reduce flexibility in communicating and performing } \\
\text { tasks. }\end{array}$ \\
\hline $\begin{array}{l}\text { Challenges } \\
\text { associated } \\
\text { with cultural } \\
\text { distance }\end{array}$ & $\begin{array}{l}\text { AC1, AC2, } \\
\text { AC3, AC4, } \\
\text { WE1, WE2, } \\
\text { EE1, EE2, } \\
\text { EE3, EE4, } \\
\text { EE5, EE6 }\end{array}$ & $\begin{array}{l}\text { Cultural differences create opportunities for misunderstanding and increase the } \\
\text { need for communication to ensure mutual understanding. } \\
\text { Language differences augment the required level of linguistic skill. } \\
\text { Cultural differences extend project duration (translation, correction of errors, etc.). }\end{array}$ \\
\hline $\begin{array}{l}\text { Impact of IT } \\
\text { on distance } \\
\text { factors }\end{array}$ & $\begin{array}{l}\text { AC1, AC2, } \\
\text { AC3, AC4, } \\
\text { WE1, WE2, } \\
\text { EE1, EE2, } \\
\text { EE3, EE4, } \\
\text { EE5, EE6 }\end{array}$ & $\begin{array}{l}\text { Technology allows information to be disseminated and stored. } \\
\text { "Virtualization" of the message overcomes barriers raised by distance in } \\
\text { kilometres. } \\
\text { Asynchronous dissemination allows barriers attributable to time zones to be } \\
\text { mastered. }\end{array}$ \\
\hline $\begin{array}{l}\text { Effects of IT } \\
\text { on } \\
\text { information } \\
\text { needs }\end{array}$ & $\begin{array}{l}\text { AC1, AC2, } \\
\text { AC4, WE1, } \\
\text { EE5 }\end{array}$ & $\begin{array}{l}\text { Technology facilitates the transmission of information necessary for performing } \\
\text { the activity and allows clearer presentation of the information and organization of } \\
\text { its content. }\end{array}$ \\
\hline \multicolumn{3}{|c|}{ Other issues raised by the respondents } \\
\hline $\begin{array}{l}\text { Perceived } \\
\text { distance }\end{array}$ & $\begin{array}{l}\text { AC1, AC2, } \\
\text { AC3, AC4, } \\
\text { WE1, WE2, } \\
\text { EE1, EE3, } \\
\text { EE4, EE5, } \\
\text { EE6 }\end{array}$ & $\begin{array}{l}\text { Perceived distance is defined as individuals appreciation of the distance } \\
\text { separating them from their business partners. } \\
\text { Perceived distance increases the cost of managing the relationship. } \\
\text { There are several contributors to perceived distance: } \\
\text { Geographical distance diminishes the possibilities for interaction and creates a } \\
\text { sense of distance. } \\
\text { Cultural misunderstandings foster a sense of distance. } \\
\text { The quality of the business relationship reduces the sense of distance. }\end{array}$ \\
\hline $\begin{array}{l}\text { Degree of } \\
\text { formalizatio } \\
\mathrm{n} \text { of the } \\
\text { message }\end{array}$ & $\begin{array}{l}\text { AC1, AC2, } \\
\text { AC3, AC4, } \\
\text { WE1, EE1, } \\
\text { EE3, EE4, } \\
\text { EE5, EE6 }\end{array}$ & $\begin{array}{l}\text { The reason for formalizing the message is to ensure that it is universally } \\
\text { understood. } \\
\text { Formalizing the message increases the cost of managing the relationship. } \\
\text { The choice of the degree of formalization of the message lies with the one who is } \\
\text { communicating: } \\
\text { Perceived distance positively affects the degree of formalization of the message. } \\
\text { The complexity of the activity increases the effort of formalization. }\end{array}$ \\
\hline
\end{tabular}




\section{Analysis}

This section analyses the results presented earlier. Links between the variables are discussed. In the spirit of Eisenhardt (1989), relevant elements in the literature that might not have been considered earlier, are included in the analysis (enfolding the literature). Similarities and differences with existing literature are highlighted to enable valuable theory building.

The model presented in Figure 2 summarizes the relationships between the variables. It shows that while cultural and geographical distance influence positively (as expected) the effort required to manage an activity offshore, it is not the sole notion of distance to consider. The notion of perceived distance has to be included in the model. This perceived distance depends on culture and geography, as well as the quality of the relationship history between client and supplier. Offshore relationships, perceived as distant, required higher level of formalization, which increased the effort. In this context, IT played a facilitating role in two different ways. First, the capacity of IT to disseminate and store information reduced the impact of geographical distance on the effort required to manage the relationship. The use of IT also reduced the need for message formalization. The technology provided automatically a certain level of formalization.

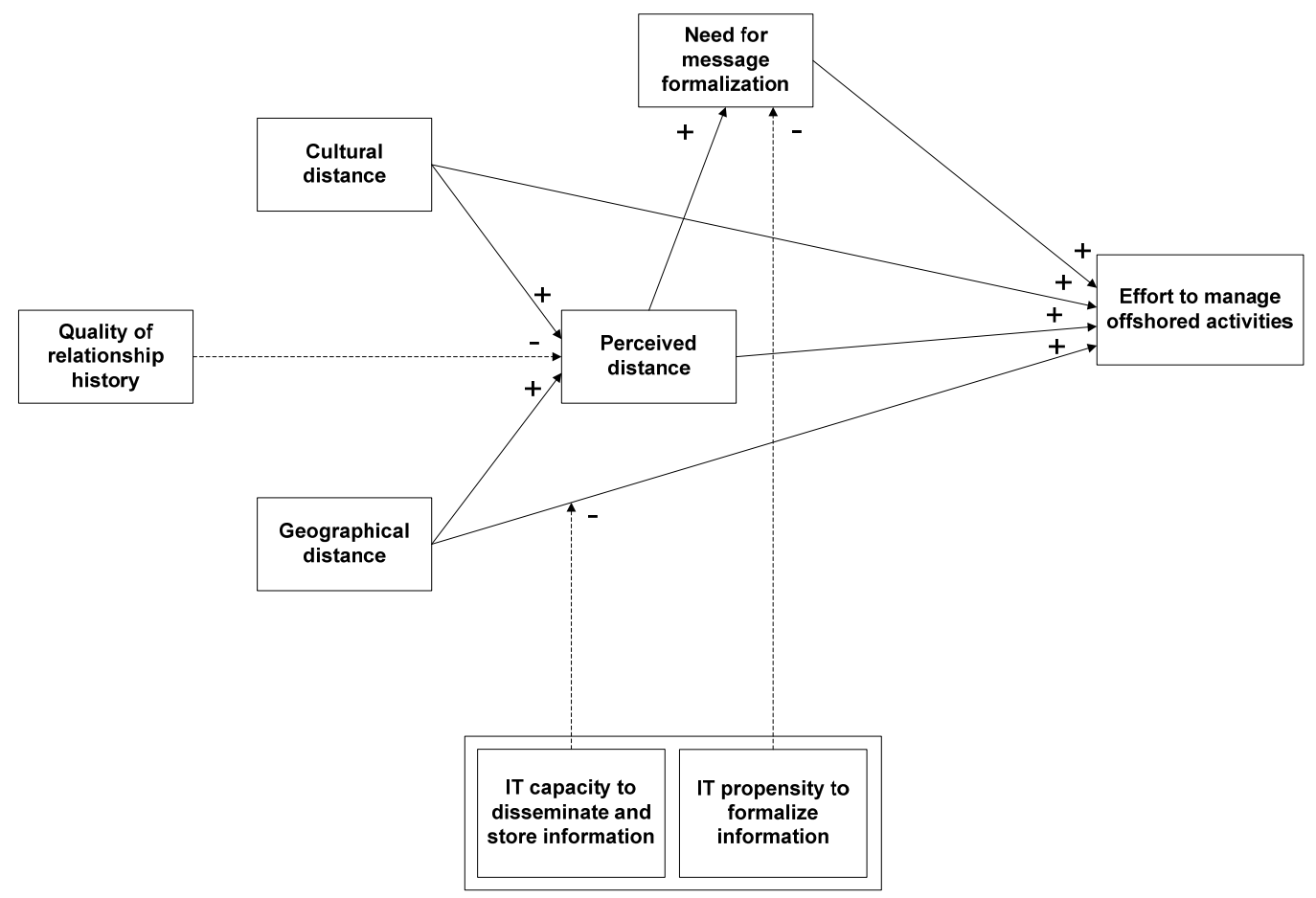

Figure 2: Theoretical Model 


\subsection{Perceived distance}

As mentioned earlier, the concept of distance discussed by the respondents was centered around the perceived distance. It was positively linked with cultural and geographical distance. It was also influenced by the quality of the relationship history between the business partners.

Cultural distance played a role, as expected. Shared values or mental representations reduced the perceived distance. At the opposite, different views increased this perceived distance. For example, a manager mentioned his irritation about the distance between his client and his own organization: "Americans totally do not understand what we are doing here. They think only from their own market understanding. They do not understand that there are different games, different rules, and different markets" (Marketing Director, EE2).

Geography also played a role in the perception of distance. Both absolute distance and time zone differences made interactions more difficult between business partners and increased the effort required to manage the relationship. Respondents from all twelve organizations mentioned the challenges associated with geography (see Table 2).

The quality of the business relationship history is a new factor that was mentioned by the respondents. A stable business relationship, showing a good record of past communication, contributed to reducing the perceived distance. Respondents perceived they were not as far to their client if they knew the persons they were dealing with, for instance when that person was a former colleague (Developer \#2, EE5). The quality of relationship history contributed to reduce the perceived distance. Similarly, a project manager mentioned that the "distance felt depended on the type of communication one had, its intensity, and frequency" (Project Manager, WE1).

This notion of perceived distance is different from the psychic distance suggested by Gurung and Prater (2006). In their model, they stated that this psychic distance is a combination of differences in language, business practices, political and legal systems, education, culture, etc. The elements suggested by these authors are stable. Findings from the cases suggest that perceived distance varies depending on past events (history).

Findings from the cases are in line with Gefen and Carmel (2008) results showing that firms were more likely to use providers who had won previous bids and less likely to use ones that had lost previous bids. They used an agency argument to support their model, relying on an adverse selection argument. The cases conducted do not contradict this possibility but they also suggest additional elements. Past providers might feel "closer" and therefore client perceive they would require less effort to manage future contracts with these past providers than with new providers. This lowers transaction costs, independently (or in addition) of adverse selection considerations.

This aspect (relationship history) is similar to findings in virtual team literature. Offshoring relationships are one form of virtual teams in which team members are positioned in the roles of client and supplier. Pauleen and Yoong (2001) found that the development of personal relationships made the work of virtual team easier. The data collected suggests that the 
offshoring arrangements follow a similar pattern. Comments made illustrate this fact: "I make sure that we start with a face-to-face meeting ..., and then we can email" or "There is one [contract] that I just closed, we didn't meet face-to-face. Humm, I guess we did, we met at a conference very quickly. But as far as talking about our services with them, it's been all over the phone, and that's unusual" (Vice-President Customer Relations, AC1).

The quality of the relationship history has been studied in relational marketing, where it was often linked to the notion of trust (Morgan and Hunt, 1994). Relationships were seen as leading with time to psychological agreements between the parties (Hunt and Morgan, 1994). Including the notion of distance might be an interesting addition in this line of work.

\subsection{Need for message formalization}

Looking at the need for message formalization is a different way to examine the relationship between the message characteristics and the media used for communication. Daft, Lengel and Trevino (1987) looked at message equivocality and found that the higher the equivocality, the stronger the preference for rich media. In the context of offshoring, it seemed that the participants recognized this relationship but often displayed a behaviour that was in the opposite direction as the one described by Daft et al. (1987). While they sometimes selected different technologies to communicate, for instance by using the telephone to clarify points after sending a document (project manager WE1) they also worked on changing their message to make it more suitable to less rich interaction: "With distance, we have to make it more formal" (Project Manager WE1). Respondents mentioned that purely technical language acted as an uncertainty reducer: "Because Java or $\mathrm{C}++$, whatever, are not different depending on the country. It's like Esperanto; it's a language everyone understands..." (Developer \#1, EE5). Therefore, the relationship between the choice of technology and message characteristics is not unidirectional.

This need of formalization, if it were solely associated with the complexity of a given activity, would have nothing to do with the context of offshoring. It would simply be a characteristic of any client-supplier arrangement. However, it seemed in the interviews that this need of message formalization was also linked to the perceived distance: the higher the perceived distance, the higher the need for message formalization.

Half of the respondents mentioned that perceived distance influenced the need for message formalization. Respondents did not communicate as formally with people they felt close to than with people they felt were further away. For example, increased perceived distance enticed respondents to ensure that documents were flawless and that there were no typos in email messages (Project Manager, AC2).

Leonardi and Bailey (2008) present some limits of IT with respect to make explicit what is at first implicit in offshore relationships. In their case study, work practices were not made explicit through the technology used by engineers, which led to misunderstandings. They suggest that 
knowledge and elements of context are embedded in the technology and that these elements have to be recognised to minimize problems.

\subsection{The role of information technology}

The interviews shed light on two properties of information technology that were particularly relevant to the offshoring context: the capacity of IT to store and disseminate information and the capacity of IT to formalize the information.

Respondents mentioned that IT enabled users to access information and to easily share it with others. The diffusion of information made physical location and enabled people to be accessible wherever they were. Technology also facilitated the diffusion of information across time barriers. The use of IT meant that communication was done even if the receptor of the information was not free at the same moment as the emitter. As one manager mentioned, "people are often on meetings here, so it's not easy to catch people in their offices" (Operation Manager, AC4). Technologies like email and project servers enabled communication to occur in this case. This means that IT, especially through its capacity to store and disseminate the information, mitigated the relationship between geographical distance and the effort to manage offshore activities. It made distant relationships easier to manage.

This aspect of IT was observed in the context of virtual teams. As Pauleen mentioned, "e-mail possesses the speed of a phone call with the paper trail of a written response." (Pauleen 2003, p. 11). This capacity of emails to join speed with completeness of information is interesting in offshoring relationships.

The second aspect is the capacity of IT to formalize information. Respondents mentioned that the use of the tools changed the information. For example, a respondent mentioned: "[With technology], I am just going straight to the point. No blablabla. It has some benefits, because you are very professional that way" (Developer \#1, EE5). The coding of the information in the IT environment made it formal. Respondents mentioned that it could reduce the potential ambiguity of the message. For instance, one respondent mentioned that emails messages did not have an accent (System Administrator, AC4). The fact that documents could be attached was also perceived to enhance clarity (Vice-President Customer Relations, AC1)..

The importance of reducing misunderstandings when mediating communication through the use of IT had been studied in the past. For instance Katz and Te'eni (2007) looked at the importance of contextualization behaviour on mutual understanding. They stated that future research would be required to understand their results in organizational settings (as opposed to laboratory environment). Offshore arrangements are such a setting. The contextualization behaviour were, in the cases done, classified under the formalization variable. Context cannot be left undocumented. All aspects have to be formalized and IT offered support for that. IT was also used to leave traces after discussions: "It is also the case with conference calls [wrapping up with a summary] and sending an email summarizing everything" (Project Manager, WE1). This behaviour reduces the likelihood of misunderstanding. 
IT also helped maintain a good relationship with business partners who were geographically distant. As mentioned by a respondent, technology cannot be used to establish a relationship, but it can be used to maintain a relationship (Project Manager, WE1). Information technology helped make interactions between parties more frequent. Respondents supported the idea that information technology reduced the effect of geographical distance on the quality of the relationship history. It made distant relationships easier to maintain.

Therefore, an aspect of IT use that would be interesting to develop is the notion of connectedness. Lindberg-Repo and Grönroos (2004) looked at the level of interaction of individuals with firms. In the case of offshoring, the comments made by the respondents suggested that this preoccupation of connectedness existed: "For me it's phone, cell phone, and blackberry, to stay connected with my clients" (Vice-President Customer Relations, AC1).

\subsection{Effort required to manage offshore activities}

Four elements were perceived to increase the effort required to manage the offshore relationship. As expected, cultural distance and geographical distance had a direct impact of the level of effort required. Also, the perceived distance increased the level of effort required. Finally, the need for message formalization increased the level of effort needed to manage the relationship.

Cultural differences lead to some additional efforts to accommodate the business partner. For example, different national holidays had to be taken into account: "if they want it on Canada day, and they want it on Victoria day... the analysts on those accounts are on American holidays instead of Canadian holidays" (Vice-President Customer Relations, AC1). It means that the company is paying mandatory bonuses and increased salaries to have its employees work on national holidays. Inefficiencies were also recognized in the processes. When discussing response time, one respondent mentioned: "In Asia, there is an expectation that you respond very quickly. In Europe, it's a little less. In the Caribbean, you can send an email, and not get a response in three or four days, because that's just how things work there" (Operation Manager, AC4). Another compared Estonians and Lithuanians, mentioning that the first group was more careful and unhurried but produced higher quality outputs, while the others were more "active" (Marketing Director, EE2).

Nooteboon (2000), looking at general governance problems associated with joint production, mentioned that cognitive distance (which could be created by cultural differences) state that bridging cognitive distance entails costs (or efforts). However, once these efforts are deployed, they can be reused to work more easily with other partners cognitively close to the first one. This, applied to the offshoring context, seems applicable. Partners used to work with another specific culture would be "equipped" to work with other clients from the same culture. Therefore, there are economies of scale when investing in the understanding of a business partner's culture. It would also mean that geographical diversification might not be desirable, since it would likely increase the number of different culture variants one company has to deal with. This might justify the development of clusters of business partners (clients or suppliers). 
Geographical distance translated in trips, visits, and time zone adjustments (which meant extra hours for local employees). All companies mentioned those costs associated with the management of an offshore business relationship.

Perceived distance forces individuals to increase communication in order to ensure that mutual understanding is achieved. This entails additional efforts. Managers dealing with clients they perceived as more "distant" spent extra efforts communicating their contribution to the activities. "I do spend a lot of time talking about the quality of the analysts, so they do understand that we are driving economies like everybody else" (Vice-President Customer Relations, AC1).

The formalization of the information entails costs to structure the project, to clarify the information requirements and to ensure that all information has been gathered. This effort is made more important as the activity formalized gains in complexity.

\section{Conclusion}

The objective of this study was to better understand the role played by some antecedents of the effort of conducting an offshore relationship. More precisely, a review of the literature led to identify three main antecedents of effort: the nature of the information that must be exchanged by the partners, the distance - cultural, geographical, and institutional - between partners, and the IT that is available to support the exchange. Interviews conducted with 19 individuals working in 12 organizations involved in offshore activities suggest the following. Cultural distance, geographic distance and the need for formalization in the information exchange indeed impacted the level of effort required to conduct an offshore relationship. Institutional distance, however, was not found to have an influence on effort. The interviews also suggested that in addition to geographic and cultural distance, perceived distance has an impact on the amount of effort required to conduct the relationship; in turn, perceived distance is influence by the actual geographic and cultural distance and by the quality of the relationship history.

This study has some implications in terms of research. First, it would be important to do further work on clarifying the notion of distance in the context of offshore relationships. Indeed, in addition to geographical, cultural, institutional, and perceived distance, the notion of "ethical distance" - referring to the role played by bribery, corruption, codes, human rights policies, etc. in the respective locations - has been proposed (Schlens and Dam 2007). Also, it would be interesting to examine how status differences between actors, which influence social boundaries (Levina and Vaast 2008), has on perceived distance. Second, a process approach could be adopted to examine how perceived distance influences effort. For instance, it has been suggested that the problems associated with cultural distance might not be related to the actual absolute distance but to the level of expectations that actors have on the behaviors of actors of a given culture (Selmer 2007). Collaborators from nearer culture would be expected to adopt appropriate behaviours while others from distant culture would not. Indeed, behaviours from a distant culture would be better tolerated because expectations are lower in this case. 
The central role played by perceived distance has a number of implications in terms of practice. The most important implication is related to the notion of the quality of the relationship history and its negative effect on perceived distance. This result suggests that entering into "one shot" offshore relationships could be detrimental in terms of the amount of efforts that the parties of the relationship have to invest in maintaining it. In addition, firms that plan to enter into offshore relationships involving the collaboration between actors from different cultural background and geographic locations should considering investing into activities that can lead to establish the basis of a relationship history of quality. The interviews conducted in this study suggest that in doing so, actors would require to spend less effort to manage the relationship.

\section{References}

Aubert, B. A., Rivard, S., and Patry, M., A transaction cost model of IT outsourcing, Information and Management, (41:7), 2004, 921-932.

Austin, T., The workplace application classification software framework. Gartner Research. ID number ; G00131005, 2005.

Baily, M. N. and Farell, D., Exploding the myths of offshoring. The McKinsey Quarterly, 2004,.

Barrett, M., Drummond, A., and Sahay, S., Exploring the impact of crosscultural differences in international software development teams : Indian expatriates in Jamaica. In Proceedings of the 4th European Conference on Information Systems, ECIS, 1996, 347-356.

Benbasat, I., D.K. Goldstein, and M. Mead, "The Case Research Strategy in Studies of Information Systems", MIS Quarterly, (11:3), 1987, 369-386.

Carlson, J., Zmud. R., Channel Expansion Theory and the Experiential Nature of Media Richness Perceptions, Academy of Management Journal, (42:2), 1999, 153-170.

Coase, R. H. The nature of the firm. Economica, 4, 1937, 386-405.

Daft, R., Lengel, R., Trevino, L.K., Message Equivocality, Media Selection, and Manager Performance: Implications for Information Systems, MIS Quarterly, (11:3), 1987, 355-366.

Drezner, D. W., The outsourcing bogeyman. Foreign Affairs, (83:3), 2004 22-34.

Eisenhardt, K. M., Building theories from case study research. The Academy of Management Review, (14:4), 1989, 532-550.

Ferguson, E., Kussmaul, C., McCracken, D. D., and Robert, M. A., Offshore outsourcing : Current conditions \& diagnosis, Proceedings of the 35th SIGCSE technical symposium on Computer science education, Norfolk, Virginia, USA, 2004 330-331. 
Gefen, D., Carmel, E., Is the World Really Flat? A look at Offshoring at an Online Programming Marketplace, MIS Quarterly, (32:2), 2008, 367-384.

Gurung, A., Prater E., A Research Framework for the Impact of Cultural Differences on It outsourcing, Journal of Global Information Technology Management, (9:1), 2006, 24-43.

Hamm, S., Big blue shift. BusinessWeek, 3987, 2006, 108-110.

Hofstede, G., Motivation, leadership, and organization : Do american theories apply abroad ? Organizationnal Dynamics, (9:1), 1980, 42.

Hunt, S. D. and Morgan, R. M. Relationship marketing in the era of network competition. Marketing Management, (3:1), 1994, 18-28.

Huntley, H. Fifteen ways to reduce risk when building an offshore outsourcing Contract, Gartner Research. ID number; G00140914.2006.

Jensen, J. B. and Kletzer, L. G., Tradable services : Understanding the scope and impact of services outsourcing. Technical Report 05-9, Institute for International Economics, 2005, 47 pages.

Katz, A., Te'eni, D., The Contingent Impact of Contextualiztion on Computer-Mediated Collaboration, Organization Science, (18:2), 2007, 261-279.

Leonardi, P., Bailey, D., Transformational Technologies and the Creation of New Work Practices: Making Implicit Knowledge Explicit in Task-Based Offshoring, MIS Quarterly, (32:2) 2008, 411436.

Levina, N., Vaast, E., Innovating or Doing as Told? Status Differences and Overlapping Boundaries in Offshore Collaboration, MIS Quarterly, (32:2), 2008, 307-332.

Licoppe, C. and Smoreda, Z., Are social networks technologically embedded ? How networks are changing today with changes in communication technology. Social Networks, 27, 2005, 317335.

Lindberg-Repo, K. and Grönroos, C. Conceptualising communications strategy from a relational perspective. Industrial Marketing Management, 33, 2004, 229-239.

Martin, P. Y. and Turner, B. A., Grounded theory and organizational research, The Journal of Applied Behavioral Science, (22:2), 1986, 141-157.

Morgan, R.M., Hunt, S. D., The Commitment-Trust Theory of Relationship Marketing, Journal of Marketing (58:3), 1994, 20-38.

Mockaitis, A. I., A Cross-Cultural Study of Leadership Attitudes in Three Baltic Sea Region Countries, International Journal of Leadership Studies, (1:1), 2005, 44-63 
Nachum, L., Zaheer, S., The persistence of Distance? The impact of Technology on MNE Motivations for Foreign Investment, Strategic Management Journal, (26), 2005, 747-767.

Naumov, A. I., Puffer, S. M., Measuring Russian Culture using Hofstede's Dimensions, Applied Psychology: an International Review, 2000, (49:4), 709-718

Nooteboom, B. (2000). Learning by interaction : Absorptive capacity, cognitive distance and governance. Journal of Management and Governance, 4(1), 69-92.

Pauleen, D. J., Lessons Learned Crossing Boundaries in an ICT-Supported Distributed Team, Journal of Global Information Management, (11:4), 2003, 1-19.

Pauleen, D. J., Yoong, P., Facilitating Virtual Team Relationships via Internet and Conventional Communication Channels, Internet Research, (11:3), 2001, 190-202.

Powell, A., Piccoli, G., and Ives, B. Virtual teams : A review of current literature and directions for future research. Database for Advances in Information Systems, (35:1), 2004,. 6-36.

Punch, L. The global back office : Beyond the hype. Credit Card Management, (16:11), 2004, pp.26.

Rao, M. T., Key issues for global IT outsourcing : Country and individual factors. Information Systems Management, (21:3), 2004, 16-20.

Rao, M.T., Poole, W., Raven P.V., Lockwood, D. L., Trends, Implications, and Responses to Global It Sourcing: A Field Study, Journal of Global Information Technology Management (9:3), 2006, 523.

Rice, R. E. and Shook, D. E., Relationships of job categories and organizational levels to use of communication channels, including electronic mail : a meta-analysis and extension. Journal of Management Studies, (27:2), 1990, 195-229.

Ronen, S. and Shenkar, O., Clustering countries on attitudinal dimensions : A review and synthesis. Academy of Management Review, (10:3), 1985, 435-454.

Rottman, J. and Lacity, M., Twenty practices for offshore sourcing. MIS Quarterly Executive, 3(3), 2004, 117-130.

Sappington, D., Incentives in principal-agent relationships. Journal of Economic Perspectives, (5:2), 1991, 45-66.

Scholtens, B., Dam, Lammertjan, Cultural Values and International Differences in Business Ethics, Journal of Business Ethics, (75), 2007, 273-284.

Scott, R., Garner, T., and Ticoll, D. (A fine balance : The impact of offshore IT services on Canada's IT landscape. PricewaterhouseCoopers, 2004. 
Selmer J, Which Is Easier, Adjusting to a Similar or to a Dissimilar Culture? American Business Expatriates in Canada and Germany, International Journal of Cross Cultural Management, (7:2), 2007, 185-201.

Trefler, D., Service offshoring : Threats and opportunities. Brookings Trade Forum 2005.

Van de Ven, A. H. and Ferry, D. L., Measuring and assessing organizations, Wiley, 1980.

Van Welsum, D. and Reif, X., Potential offhoring : Evidence from selected OECD countries. Brookings Trade Forum 2005.

Watson-Manheim, M.B., Bélanger, F., Communication Media Repertoires: Dealing with the Multiplicity of Media Choices, MIS Quarterly, (31 :2) 2007, 267-393.

Williamson, O. E. The Economic Institutions of Capitalism, Free Press, New York, NY, 1985. 


\section{Appendix 1 - Interview Protocol}

\section{Organization}

- What is the mission of your organization?

- What is the structure of your organization?

- What is your function in the firm?

- Do you have some special selection criteria for recruitment?

- What kinds of activities are performed by your workgroup?

\section{Communication challenges}

- What are the main challenges you have met when you were realizing activities for your clients?

- Did you encounter difficulties to communicate with your clients?

- How are your clients doing any control on your work?

- What is the frequency of contacts between you and your clients?

- Have you ever met your clients face-to-face?

Technology

- What kind of technologies are you using in order to perform your activities?

- How do you use the technological tools you have access to?

\section{Geography}

- What is the distance in kilometers between you and your clients?

- Are you working in the same time zone than your clients?

- Do the geographic distance change the way you work?

- Do the geographic distance change the way you use the technology?

\section{Culture}

- Do you think there are cultural differences in the way you work or communicate between you and your clients?

- Do you have any example of past misunderstandings due to cultural criteria?

- What is the language used when you meet your clients?

- Do the cultural distance change the way you work?

- Do the cultural distance change the way you use the technology?

\section{Institutions}

- Are you and your clients respectively submitted to different norms and laws?

- Up to now, did your organization modify or adapt some rules or way of working with respect to institutional issues?

Perceived distance (added after the first round of interviews - Atlantic Canada - and first round of analysis)

- Do you think there is a distance between you and your clients?

- Do the perceived distance change the way you work?

- Do the geographic distance change the way you use the technology? 